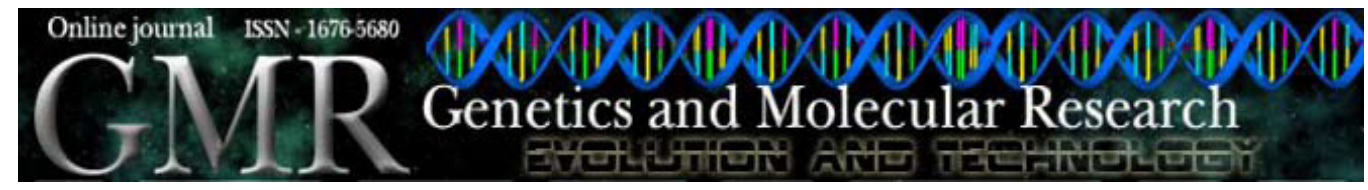

\title{
Lack of association between glutathione S-transferase polymorphisms and primary glioma in a case-control study in Rio de Janeiro
}

\author{
P. Coutinho' ${ }^{1}$, V. Sandim ${ }^{2,4}$, J.A. Oliveira ${ }^{3}$, G. Alves ${ }^{2}$ and A. Hatagima ${ }^{1}$ \\ ${ }^{1}$ Laboratório de Genética Humana, Instituto Oswaldo Cruz/FIOCRUZ, \\ Rio de Janeiro, RJ, Brasil \\ ${ }^{2}$ Laboratório de Genética Aplicada, Serviço de Hematologia, \\ Instituto Nacional de Câncer (INCA), Rio de Janeiro, RJ, Brasil \\ ${ }^{3}$ Serviço de Neurocirurgia, INCA, Rio de Janeiro, RJ, Brasil \\ ${ }^{4}$ Departamento de Bioquímica Médica, UFRJ, Rio de Janeiro, RJ, Brasil \\ Corresponding author: A. Hatagima \\ E-mail: ahatagima@gmail.com
}

Genet. Mol. Res. 9 (1): 539-544 (2010)

Received December 1, 2009

Accepted January 11, 2010

Published March 23, 2010

\begin{abstract}
The glutathione S-transferases (GSTs), a family of phase II isozymes, detoxify several carcinogens. Genetic variations in GSTs have been associated with increased risk for cancer due to a heritable deficiency in detoxification pathways for environmental carcinogens. Conflicting findings have been reported about the association between constitutive GST polymorphisms and gliomas in different populations. The present case-control study examined 78 patients with primary glioma and 347 controls from Rio de Janeiro. DNA was isolated from whole blood, and four genetic polymorphisms (GSTM1, GSTM3, GSTT1, and GSTP1) were determined by PCR-RFLP. The distributions of the genotypic frequencies of these polymorphisms did not differ significantly between cases and controls and were as expected by Hardy-Weinberg equilibrium $(\mathrm{P}>0.05)$. Risk analysis did not show an association between GSTs and primary glioma, suggesting that these polymorphisms do not influence the risk of primary glioma, at least in this population in Rio de Janeiro, Brazil.
\end{abstract}

Key words: Glioma; Gluthatione S-transferase; Genetic polymorphisms 


\section{INTRODUCTION}

Gliomas represent a heterogeneous group of diseases whose etiology is very poorly understood. There is some evidence that environmental/occupational exposure and DNA damage may be a potential neurocarcinogenic factor (De Roos et al., 2003; Pinarbasi et al., 2005), suggesting the importance of the detoxification process. Polymorphisms in the glutathione S-transferase (GST) genes, a superfamily of enzymes that plays a key role in carcinogen metabolism, have been associated with cancer risk (De Roos et al., 2006). The GSTM1 and GSTT1 genes have been considered important modifiers of individual risk of environmentally induced cancers, since homozygotes for GSTM1*0 or GSTT1*0 alleles (null genotypes) do not show the respective proteins (Seidegard et al., 1988; Pemple et al., 1994). GSTP1-I105V polymorphism causes lower affinity for electrophilic substrates and heat stability compared with the wild type (Ali-Osman et al., 1997), and variations in GSTM3, the predominant mu class enzyme in human brain cytosol, may affect the regulation, amount and activity of GSTM3, and may have distinct effects on cancer susceptibility (Inskip et al., 1995). In this study, we examined the GSTM1, GSTM3, GSTT1, and GSTP1-I105V allelic and genotypic distributions in a case-control Brazilian sample from Rio de Janeiro, and investigated the relationship between GST polymorphisms and risk of primary glioma.

\section{MATERIAL AND METHODS}

\section{Subjects}

A total of 78 primary glioma patients seen at the Instituto Nacional de Câncer (INCA) in Rio de Janeiro from 1998 to 2000 were studied. DNA from blood was extracted and stored at $-20^{\circ} \mathrm{C}$. Patients with immunodeficiency problems, previous mental illness or genetic syndromes were excluded. Diagnosis was carried out during surgery by a pathologist and later confirmed by the Pathology Service of INCA, according to the brain tumor classification of the World Health Organization (WHO). Among the 78 glioma cases, 5 were pilocytic astrocytoma, 28 astrocytomas grade II, 22 astrocytomas grade III, 16 glioblastomas, 4 ependymomas, and 3 oligodendrogliomas grades II and III. The control group consisted of 347 unrelated blood donors who were recruited at Clementino Fraga Filho Hospital in Rio de Janeiro. All procedures were approved by the Institute's Research Ethics Committee and included informed consent from participating individuals (if children, from their parents).

\section{Genotyping}

Genetic polymorphisms were assessed in DNA extracted from white blood cells, by previously described PCR-RFLP protocols (Fryer et al., 1993; Pemple et al., 1994; Inskip et al., 1995; Nedelcheva Kristensen et al., 1998), with minor modifications (Table 1). In brief, the amplification of target DNA was achieved by PCR optimized conditions as follows: a final reaction volume of $30 \mu \mathrm{L}$ was composed of 50-100 ng DNA, $200 \mu \mathrm{M}$ of each dTNP, $1 \mathrm{U}$ Taq DNA polymerase and 1X PCR buffer (Biotools ${ }^{\mathrm{TM}}$ ), and 20 pmol of each primer. Negative controls were included in every run, and the success of amplification was confirmed on $1.5 \%$ agarose gels stained with ethidium bromide and visualized under ultraviolet (UV) light. Endonuclease digestions were performed similarly, using overnight $37^{\circ} \mathrm{C}$ incubation conditions (New England Biolabs ${ }^{\mathrm{TM}}$, according to manufacturer recommendations). Determination of genotypes was performed on either $2.5 \%$ agarose or $10 \%$ acrylamide gels, stained 
with ethidium bromide and visualized under UV light. Reproducibility of genotyping was accessed by conducting duplicate experiments, and all genotyping was determined blind to case-control status.

\begin{tabular}{|c|c|c|c|c|c|}
\hline Gene & Primer sequence (5'-3') & $\begin{array}{l}\text { Annealing } \\
\text { temperature }\end{array}$ & $\begin{array}{l}\text { Amplified } \\
\text { product }\end{array}$ & Endonuclease & References \\
\hline GSTMI & $\begin{array}{l}\text { F-GCTTCACGTGTTATGAAGGTTC } \\
\mathrm{R}_{1} \text {-TTGGGAAGGCGTCCAAGCGC } \\
\mathrm{R}_{2} \text {-TTGGGAAGGCGTCCAAGCAG }\end{array}$ & $57^{\circ} \mathrm{C}$ & $132 \mathrm{bp}$ & - & (Fryer et al., 1993) \\
\hline GSTT1 & $\begin{array}{l}\text { F-TTCCTTACTGGTCCTCACATCTC } \\
\text { R-TCACCGGATCATGGCCAGCA }\end{array}$ & $60^{\circ} \mathrm{C}$ & $480 \mathrm{bp}$ & - & (Pemble et al., 1994) \\
\hline GSTM3 & $\begin{array}{l}\text { F-CCTCAGTACTTGGAAGAGCT } \\
\text { R-CACATGAAAGCCTTCAGGTT }\end{array}$ & $58^{\circ} \mathrm{C}$ & $273 / 270 \mathrm{bp}$ & $M n l \mathrm{I}$ & (Inskip et al., 1995) \\
\hline GSTP1 & $\begin{array}{l}\text { F-TCCTTCCACGCACATCCTCT } \\
\text { R-AGCCCCTTTCTTTGTTCAGC }\end{array}$ & $68^{\circ} \mathrm{C}$ & 294 bp & BsmAI & (Nedelcheva Kristensen et al., 1998) \\
\hline
\end{tabular}

$\mathrm{F}=$ forward sequence; $\mathrm{R}=$ reverse sequence.

\section{Statistical analysis}

The maximum likelihood method was used to estimate the allelic frequencies. The goodness of fit of genotype distribution to Hardy-Weinberg equilibrium was ascertained by the chi-square test. Comparison between case-control groups was performed using contingency tables analyzed by the chi-square test or the Fisher exact test. Epi-Info version 6.0 was used to estimate odds ratios (OR) and confidence intervals (CI) at the 95\% significance level.

\section{RESULTS}

A total of 425 individuals ( 78 glioma cases and 347 controls) were analyzed for GSTM1, GSTT1, GSTP1, and GSTM3 polymorphisms. The proportion of males was $49 \%$ in cases and $54 \%$ in controls. Mean age ( \pm standard deviation) was $37.26 \pm 22.75$ years among cases, age range 3-84 years, and $40.48 \pm 11.31$ years among controls, age range 18-60 years. The distribution of GST genotypes in cases and controls are shown in Table 2 . There were no statistically significant differences in the distribution of GST genotypes between cases and controls. Both groups showed a good fit to Hardy-Weinberg's genetic equilibrium model in relation to observed and expected genotypic frequencies for all the GSTs studied. The crude risk analyses did not detect a statistically significant effect of the polymorphisms studied on the risk of glioma (Table 2).

\begin{tabular}{|c|c|c|c|c|}
\hline Gene & Genotype & Cases, N (\%) & Controls, N (\%) & OR $(95 \% \mathrm{CI})$ \\
\hline \multirow[t]{2}{*}{ GSTMI } & Present & $41(53 \%)$ & $194(56 \%)$ & 1 \\
\hline & Null & $37(47 \%)$ & $153(44 \%)$ & $1.14(0.68-1.93)$ \\
\hline \multirow[t]{2}{*}{ GSTT1 } & Present & $67(86 \%)$ & $271(78 \%)$ & 1 \\
\hline & Null & $11(14 \%)$ & $76(22 \%)$ & $0.59(0.28-1.21)$ \\
\hline \multirow[t]{4}{*}{ GSTM3 } & AA & $47(60 \%)$ & $180(52 \%)$ & 1 \\
\hline & $\mathrm{AB}$ & $24(31 \%)$ & $134(39 \%)$ & $0.69(0.39-1.22)$ \\
\hline & BB & $7(9 \%)$ & $33(9 \%)$ & $0.81(0.31-2.07)$ \\
\hline & $\mathrm{AB}+\mathrm{BB}$ & $31(40 \%)$ & $167(48 \%)$ & $0.71(0.42-1.21)$ \\
\hline \multirow[t]{4}{*}{ GSTP1-I105V } & $\mathrm{AA}$ & $35(45 \%)$ & $129(37 \%)$ & 1 \\
\hline & $\mathrm{AG}$ & $37(47 \%)$ & $172(50 \%)$ & $0.79(0.46-1.37)$ \\
\hline & GG & $6(8 \%)$ & $46(13 \%)$ & $0.48(0.17-1.30)$ \\
\hline & $\mathrm{AG}+\mathrm{GG}$ & $43(55 \%)$ & $218(63 \%)$ & $0.73(0.43-1.23)$ \\
\hline
\end{tabular}




\section{DISCUSSION}

In the present study, we assessed the influence of GST polymorphisms on susceptibility to the development of primary glioma. The genotype frequency distributions of GSTM1, GSTT1, GSTP1, and GSTM3 polymorphisms, in cases and controls, did not show statistically significant differences, suggesting that the GSTM1 null, GSTT1 null, GSTM3 B/B, and GSTP1-105 Val/Val genotypes do not influence the risk of primary glioma in Rio de Janeiro. Previous studies have shown that the GSTT1 polymorphism may play a role in the development of oligodendroglioma $(\mathrm{OR}=3.2$; $95 \% \mathrm{CI}=1.1-9.2)$, astrocytoma $(\mathrm{OR}=2.67 ; 95 \% \mathrm{CI}=1.53-4.65)$ and meningioma (OR $=4.52 ; 95 \% \mathrm{CI}=2.18-9.34$ ) in Caucasians (Elexpuru-Camiruaga et al., 1995; Kelsey et al., 1997). De Roos et al. (2003) observed an increased risk for glioma associated with the GSTP1-105 Val/Val genotype $(\mathrm{OR}=1.8 ; 95 \% \mathrm{CI}=1.2-2.7)$ in Americans. Later, Pinarbasi et al. (2005) found an association of GSTM1 null genotype with brain cancer $(\mathrm{OR}=2.33 ; 95 \% \mathrm{CI}=1.24-4.39)$ in a Turkish population.

However, Schwartzbaum et al. (2007) did not find any association between GSTs polymorphisms and adult brain tumor risk in 725 patients and 1612 controls from Europe. Other studies corroborate these findings (De Roos et al., 2003; Butler et al., 2003; Lanciotti et al., 2005), including the present one. In addition, a meta-analysis study including eight publications from different world populations gathering a total of 1630 cases of glioma and 7151 controls, did not find an association between the GSTM1, GSTT1, GSTP1 variants and the risk of glioma (Lai et al., 2005).

A small number of studies have assessed the relation of GSTM3 with brain cancer, though this polymorphism is the predominant mu class enzyme in human brain cytosol. Our results do not show an association of GSTM3 with risk of glioma and corroborate previous studies (Hand et al., 1996; Schwartzbaum et al., 2007). However, a large hospital-based case-control study observed an increased risk of glioma (OR $=2.3 ; 95 \% \mathrm{CI}=1.0-5.2$ ) associated with the GSTM3 B/B genotype (De Roos et al., 2006).

The divergence of the observed results may be due to several factors such as the sample size, environmental exposure differences in the studied populations, diversity of glioma histopathology, and the population genetic background. The evaluation of combined effects of other susceptibility factors, including polymorphisms of phase I carcinogen metabolizing enzymes and environmental exposures, conducted in a large number study populations will help to provide clues for the understanding of genetic and environmental determinants of brain tumors. Furthermore, GST variants show substantial variations in frequencies based on ethnic groups and geographical regions (Garte et al., 2001; Roy et al., 2001). Brazilians form one of the most heterogeneous populations of the world, as a result of the mixture of different ethnic groups that occurred throughout the colonization of Brazil since the year 1500 (Carvalho-Silva et al., 2001). The genotype frequency distribution of one region depends on the proportion of each ethnic group, which may vary in different regions of the country (Carvalho-Silva et al., 2001; Hatagima et al., 2004). The above considerations emphasize the importance of new casecontrol studies in different populations, in order to try to elucidate the true role of GST polymorphisms in the risk of developing cancer. 
The frequency distributions of GSTM1, GSTM3, GSTT1, and GSTP1-I105V in the present study did not show any statistically significant difference between cases and controls, suggesting that these polymorphisms do not influence the risk of primary glioma in Rio de Janeiro.

\section{ACKNOWLEDGMENTS}

Research supported by Fundação Oswaldo Cruz (FIOCRUZ - Rio de Janeiro), Conselho Nacional de Desenvolvimento Científico e Tecnológico (CNPq - Brasília) and Instituto Nacional do Câncer (INCA - Rio de Janeiro).

\section{REFERENCES}

Ali-Osman F, Akande O, Antoun G, Mao JX, et al. (1997). Molecular cloning, characterization, and expression in Escherichia coli of full-length cDNAs of three human glutathione S-transferase Pi gene variants. Evidence for differential catalytic activity of the encoded proteins. J. Biol. Chem. 272: 10004-10012.

Butler MA, Ruder AM, Daly AK, Waters MA, et al. (2003). Polymorphisms in GSTM1, GSTT1, GSTP1 and NAT2 and susceptibility to primary intracranial brain gliomas. Presented at AACR, Washington, D.C., August 2003. Proc. Am. Assoc. Cancer Res. 44: 128.

Carvalho-Silva DR, Santos FR, Rocha J and Pena SD (2001). The phylogeography of Brazilian Y-chromosome lineages. Am. J. Hum. Genet. 68: 281-286.

De Roos AJ, Rothman N, Inskip PD, Linet MS, et al. (2003). Genetic polymorphisms in GSTM1, -P1, -T1, and CYP2E1 and the risk of adult brain tumors. Cancer Epidemiol. Biomarkers Prev. 12: 14-22.

De Roos AJ, Rothman N, Brown M, Bell DA, et al. (2006). Variation in genes relevant to aromatic hydrocarbon metabolism and the risk of adult brain tumors. Neuro-Oncol. 8: 145-155.

Elexpuru-Camiruaga J, Buxton N, Kandula V, Dias PS, et al. (1995). Susceptibility to astrocytoma and meningioma: influence of allelism at glutathione S-transferase (GSTT1 and GSTM1) and cytochrome P-450 (CYP2D6) loci. Cancer Res. 55: 4237-4239.

Fryer AA, Zhao L, Alldersea J, Pearson WR, et al. (1993). Use of site-directed mutagenesis of allele-specific PCR primers to identify the GSTM1 A, GSTM1 B, GSTM1 A,B and GSTM1 null polymorphisms at the glutathione S-transferase, GSTM1 locus. Biochem. J. 295 (Pt 1): 313-315.

Garte S, Gaspari L, Alexandrie AK, Ambrosone C, et al. (2001). Metabolic gene polymorphism frequencies in control populations. Cancer Epidemiol. Biomarkers Prev. 10: 1239-1248.

Hand PA, Inskip A, Gilford J, Alldersea J, et al. (1996). Allelism at the glutathione S-transferase GSTM3 locus: interactions with GSTM1 and GSTT1 as risk factors for astrocytoma. Carcinogenesis 17: 1919-1922.

Hatagima A, Marques CF, Krieger H and Feitosa MF (2004). Glutathione S-transferase M1 (GSTM1) and T1 (GSTT1) polymorphisms in a Brazilian mixed population. Hum. Biol. 76: 937-942.

Inskip A, Elexperu-Camiruaga J, Buxton N, Dias PS, et al. (1995). Identification of polymorphism at the glutathione S-transferase, GSTM3 locus: evidence for linkage with GSTM1*A. Biochem. J. 312 (Pt 3): 713-716.

Kelsey KT, Wrensch M, Zuo ZF, Miike R, et al. (1997). A population-based case-control study of the CYP2D6 and GSTT1 polymorphisms and malignant brain tumors. Pharmacogenetics 7: 463-468.

Lai R, Crevier L and Thabane L (2005). Genetic polymorphisms of glutathione S-transferases and the risk of adult brain tumors: a meta-analysis. Cancer Epidemiol. Biomarkers Prev. 14: 1784-1790.

Lanciotti M, Coco S, Michele PD, Haupt R, et al. (2005). Glutathione S-transferase polymorphisms and susceptibility to neuroblastoma. Pharmacogenet. Genomics 15: 423-426.

Nedelcheva Kristensen V, Andersen TI, Erikstein B, Geitvik G, et al. (1998). Single tube multiplex polymerase chain reaction genotype analysis of GSTM1, GSTT1 and GSTP1: relation of genotypes to TP53 tumor status and clinicopathological variables in breast cancer patients. Pharmacogenetics 8: 441-447.

Pemble S, Schroeder KR, Spencer SR, Meyer DJ, et al. (1994). Human glutathione S-transferase theta (GSTT1): cDNA cloning and the characterization of a genetic polymorphism. Biochem. J. 300 (Pt 1): 271-276.

Pinarbasi H, Silig Y and Gurelik M (2005). Genetic polymorphisms of GSTs and their association with primary brain tumor incidence. Cancer Genet. Cytogenet. 156: 144-149.

Roy B, Majumder PP, Dey B, Chakraborty M, et al. (2001). Ethnic differences in distributions of GSTM1 and GSTT1 
homozygous "null" genotypes in India. Hum. Biol. 73: 443-450.

Schwartzbaum JA, Ahlbom A, Lonn S, Warholm M, et al. (2007). An international case-control study of glutathione transferase and functionally related polymorphisms and risk of primary adult brain tumors. Cancer Epidemiol. Biomarkers Prev. 16: 559-565.

Seidegard J, Vorachek WR, Pero RW and Pearson WR (1988). Hereditary differences in the expression of the human glutathione transferase active on trans-stilbene oxide are due to a gene deletion. Proc. Natl. Acad. Sci. U. S. A. 85: 7293-7297. 